\title{
Knowledge of Computer Ergonomics among Computer Science Engineering and Information Technology Students in Karnataka, India
}

\author{
Mohamed Sherif Sirajudeen ${ }^{1 *}$ and Shaikhji Saad Mohamed Siddik ${ }^{2}$ \\ 'Department of Physical Therapy and Health Rehabilitation, College of Applied Medical Sciences, Majmaah \\ University, Al Majmaah, Riyadh, Saudi Arabia; m.sirajudeen@mu.edu.sa \\ ${ }^{2}$ Yenepoya Physiotherapy College, Yenepoya University, Mangalore - 575018, Karnataka, India; \\ shaikhjisaad@gmail.com
}

\begin{abstract}
Ergonomics is the science of designing the job to fit the worker. Neglect of ergonomic principles results in inefficiency and pain in the workplace. The objective of this research is to assess the knowledge of Computer Ergonomics among Computer Science Engineering and Information Technology Students in Karnataka. In this Cross-sectional study, 177 Computer Science Engineering and Information Technology Students were recruited. A questionnaire is used to gather details regarding Personal characteristics, Computer Usage and Knowledge of Ergonomics. Descriptive statistics was produced for Personal characteristics and Computer usage. The distribution of responses to the items related to Ergonomic knowledge was presented by percentage of the subjects who answered correctly. The results shows that Majority of the subjects were unaware of ergonomics (32.8\% correct responses), cumulative trauma disorders (18.6\% correct responses), healthy postures related to elbow (34.4\% correct responses), wrist \& hand (39.5\% correct responses), Level of Monitor (35\% correct responses), Position of mouse ( $47.4 \%$ correct responses) and Mini breaks ( $42.9 \%$ correct responses). This research highlighted the necessity of Ergonomic training regarding healthy postures and the measures to reduce the risk of musculoskeletal disorders for the students.
\end{abstract}

Keywords: Computer Users, Ergonomics, Knowledge, Engineering Students

\section{Introduction}

Ergonomics is the scientific study of human work ${ }^{1}$. More specifically, ergonomics is the science of designing the job to fit the worker rather than physically forcing the worker's body to fit the job. Practice of ergonomics improves working efficiency, comfort and easiness to use without compromising health and safety. A workplace, which is ergonomically deficient, may not cause immediate pain, because the human body can adapt to a poorly designed workplace to some extent. However, in long term, the workplace deficiencies will surpass the body's coping mechanisms, resulting in pain, mental stress, decreased performance and poor quality of work ${ }^{2,3}$. Neglecting these issues can result in disabling injuries urging one to change one's profession.

In the current world, it's almost impossible to imagine that someone can live without computers. They have become an electronic device of almost every day use for individuals of every age. Inappropriate use of computer increase the risk of health problems. Working for prolonged period in an ergonomically deficient work place can lead to Musculoskeletal Disorders (MSDs). Globally over the past decade, there is 25 percent increase in the individuals suffering from musculoskeletal conditions ${ }^{4}$. Ergonomics emerges as a concern because majority of these musculoskeletal conditions are related to computer $u e^{5}$. Improper workstation design and faulty posture are

${ }^{*}$ Author for correspondence 
risk factors related to computer use. Extended period of static sitting postures causes decreased circulation, stiffness and pain in the joints. Prolonged duration of continuous work increases the risk of cumulative trauma disorders, which may result in long-term disability ${ }^{5}$. A little knowledge of the principles of ergonomics of work station setup and exercises can prevent a lot of discomfort and maximize productivity.

In India, Ergonomics is a relatively novel concept and yet to be considered by most enterprises as an essential component. In the absence of any formal ergonomic orientation /education, the present study, first of its kind in India, aimed at identifying the knowledge of computer ergonomics among Computer Science Engineering and Information Technology Students studying in Mangalore. Students are the future workers and they are more likely to enter the work force with poor computing habits or even a MSD without some intervention, hence the findings of this study can form a foundation for future research and ergonomic training and prepare the students to enter the work force and excel in their chosen professions.

\section{Materials and Methods}

\subsection{Subjects and Study Design}

In this Cross-sectional study, 177 Computer Science Engineering and Information Technology Students from a private engineering college in Mangalore were recruited using convenience sampling technique. The target sample size was based on the assumption of knowledge about Computer ergonomics to be $50 \%, 95 \%$ confidence interval and relative precision of $20 \%$. Third and fourth year students (both male and female) were included and the students who are not willing to participate were excluded from the study. 177 students met the selection criteria and were briefed about the objective of the study. All the 177 students were willing to participate in the study and their informed consent was obtained. A valid, reliable, pre-tested self-administered questionnaire was used to gather details regarding Personal characteristics, Computer Usage and Knowledge of Ergonomics ${ }^{6-8}$. The researchers were available to clear any doubts regarding the items of the questionnaire. All the 177 students completed the questionnaire and the data was entered into the Microsoft excel sheet for analysis. The study was approved by Yenepoya University Ethics Committee.

\subsection{Questionnaire Details}

\subsubsection{Personal Characteristics}

This section consists of a series of personal characteristic items like age, gender, height, weight, Body Mass Index (BMI).

\subsubsection{Computer Usage}

The details regarding weekly computer use, weekly keying $\&$ mouse usage, desktop and or laptop usage for academic and nonacademic purpose and usage of external keyboard and external mouse were also assessed in this section.

\subsubsection{Ergonomic Knowledge}

This section of the questionnaire consisted of 35 items related to knowledge about musculoskeletal disorders and its risk factors, working postures, seating, keyboard/ mouse, monitor, table and accessories and finally rest breaks and exercises. The section related to knowledge about musculoskeletal disorders and its risk factors composed of 3 Multiple Choice Questions (MCQ) and 2 true or false ( $\mathrm{T}$ or $\mathrm{F}$ ) questions related to definition of ergonomics, cumulative trauma disorders, goal of ergonomics, signs and symptoms of musculoskeletal disorders and its risk factors.

The working postures section composed of 1 MCQ and $4 \mathrm{~T}$ or $\mathrm{F}$ questions related to head, neck and trunk, upper arm and elbow, wrist and hand, thigh and finally feet. The seating (Chair) section composed of 3 MCQs and $2 \mathrm{~T}$ or $\mathrm{F}$ questions related to adjustable back rest, low back support, seat height, seat pan and finally base of the chair. The key board/ mouse section composed of 3 MCQs and 2 T or F questions related to key board level, mouse size, mouse grip, mouse placement and finally ideal mouse pad.

The monitor section composed of 3 MCQs and $2 \mathrm{~T}$ or F questions related to monitor's position, level (height), tilt, distance (from the user) and finally presence of glare. The table and accessories section composed of 3 MCQs and $2 \mathrm{~T}$ or $\mathrm{F}$ questions related to placement of telephone and documents, document holder, telephone usage, edge of table's top and finally leg room under the table. The rest breaks and exercises section composed of 3 MCQs and $2 \mathrm{~T}$ or $\mathrm{F}$ questions related to periodically alternating 
computer tasks, micro breaks, mini breaks, stretching and finally eye exercises.

\subsection{Statistical Analysis}

Descriptive statistics was produced for Personal characteristics and Computer usage. The distribution of responses to the items related to Ergonomic awareness was presented by percentage of the subjects who answered correctly.

\section{Results}

\subsection{Personal Characteristics}

Table 1 show the details regarding Personal characteristics of the 177 subjects participated in this study. Among the subjects most of them were females $(72.3 \%)$ and males were (27.7\%). Mean age of subjects was $20.21 \mathrm{yr}$, height $163.14 \mathrm{~cm}$. and weight $53.7 \mathrm{Kg}$. $65 \%$ of the subjects were normal in BMI, $29.9 \%$ of subjects were underweight $5.1 \%$ of them were overweight, and none of the subjects were obese.

Table 1. Personal characteristics

\begin{tabular}{lcc}
\hline Characteristics & Mean & Standard deviation \\
\hline Age (Yrs.) & 20.21 & 0.99 \\
Height (Cms) & 163.14 & 8.57 \\
Weight (Kgs) & 53.7 & 9.52 \\
\hline \multicolumn{2}{l}{ Number } & Percentage \\
\hline Gender & & \\
Male & 49 & 27.7 \\
Female & 128 & 72.3 \\
BMI & & \\
Less than 18.5 - Under- & 53 & 29.9 \\
weight & & \\
18.5-24.99 - Normal & 115 & 65 \\
25-29.99 - Overweight & 9 & 5.1 \\
30 or above - Obese & 0 & 0 \\
\hline
\end{tabular}

\subsection{Computer Usage}

Table 2 lists the details regarding the computer usage of the participants. The total use of computer in past was reported as 3.2 years. The average weekly computer usage was reported as $18.17 \mathrm{hrs} / \mathrm{wk}$. The weekly usage of Desktop and Laptop was reported as $8.7 \mathrm{hrs} / \mathrm{wk}$. and 9.5 hrs/wk. respectively. The average weekly usage hours of computer for nonacademic purpose were reported as $\mathbf{1 1 . 2}$ hrs/wk. The average weekly keying usages for Desktop and Laptop were reported as 5.1 hours and 3.7 hours respectively. The average mouse usage was reported as $5.4 \mathrm{hrs} / \mathrm{wk} .9 \%$ of the subjects reported of using External keyboard and 31.6\% reported of using External Mouse while using laptop.

Table 2. Computer usage

\begin{tabular}{|c|c|c|c|}
\hline Characteristics & \multicolumn{2}{|c|}{ Mean } & $\begin{array}{l}\text { Standard } \\
\text { deviation }\end{array}$ \\
\hline Computer use (yrs.) $)^{\#}$ & \multicolumn{2}{|c|}{3.23} & 2.39 \\
\hline Computer use (hrs/wk.)* & \multicolumn{2}{|c|}{18.17} & 11.13 \\
\hline Desktop (hrs/wk.) & \multicolumn{2}{|c|}{8.7} & 5.8 \\
\hline Laptop (hrs/wk.) & \multicolumn{2}{|c|}{9.5} & 10.95 \\
\hline Non-academic use (hrs/wk.)* & \multicolumn{2}{|c|}{11.2} & 13.3 \\
\hline \multicolumn{4}{|l|}{ Keying } \\
\hline Desktop (hrs/wk.) & \multicolumn{2}{|c|}{5.1} & 4.3 \\
\hline Laptop (hrs/wk.) & \multicolumn{2}{|c|}{3.7} & 5.9 \\
\hline \multirow[t]{2}{*}{ Mouse (hrs/wk.) } & \multicolumn{2}{|c|}{5.4} & 5.9 \\
\hline & \multicolumn{2}{|c|}{ Number } & Percentage \\
\hline \multicolumn{4}{|c|}{ Laptop } \\
\hline \multirow[t]{2}{*}{ Use External keyboard } & Yes & 16 & 9.0 \\
\hline & No & 161 & 91 \\
\hline \multirow[t]{2}{*}{ Use External mouse } & Yes & 56 & 31.6 \\
\hline & No & 121 & 68.4 \\
\hline
\end{tabular}

\# - used computer for more than $10 \mathrm{hrs} / \mathrm{wk},{ }^{*}$ - desktop+laptop

\subsection{Ergonomic Knowledge}

The distribution of responses to the items was presented by percentage of the subjects who answered correctly. The results are presented under 7 sections as shown in Figure 1-7. The results of this study show that majority of the subjects were unaware of ergonomics $(32.8 \%$ correct responses) and cumulative trauma disorders (18.6\% correct responses) (Figure 1). Majority of the subjects were unaware of healthy postures related to elbow (34.4\% correct responses), wrist and hand (39.5\% correct responses). (Figure 2) Majority of the subjects were unaware of seating on a chair with 5 legged base with caster wheels (27.1\% correct responses) (Figure 3). Majority of subjects were not aware of position of mouse (47.4\% correct responses) (Figure 4). Majority of subjects were also unaware of position of Monitor with respect to eye level ( $35 \%$ correct responses), about the tilt of monitor (28.8\% correct responses) (Figure 5). And mini breaks (42.9\% correct responses) as shown in (Figure 7). 


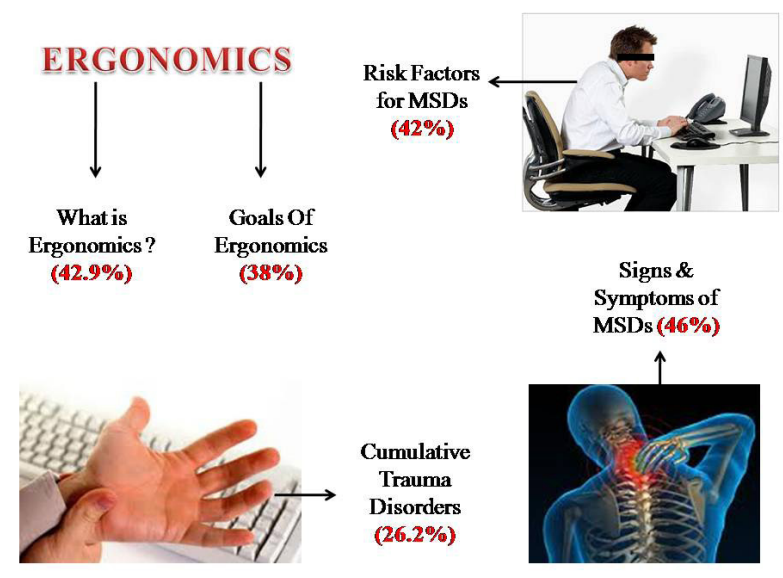

Figure 1. Knowledge about musculoskeletal disorders and its risk factors.

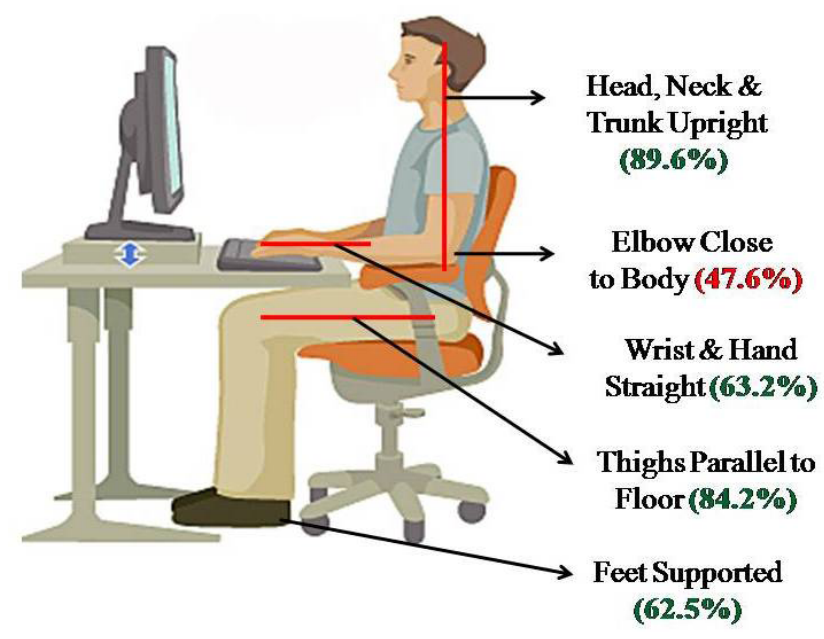

Figure 2. Ergonomic knowledge related to working postures.

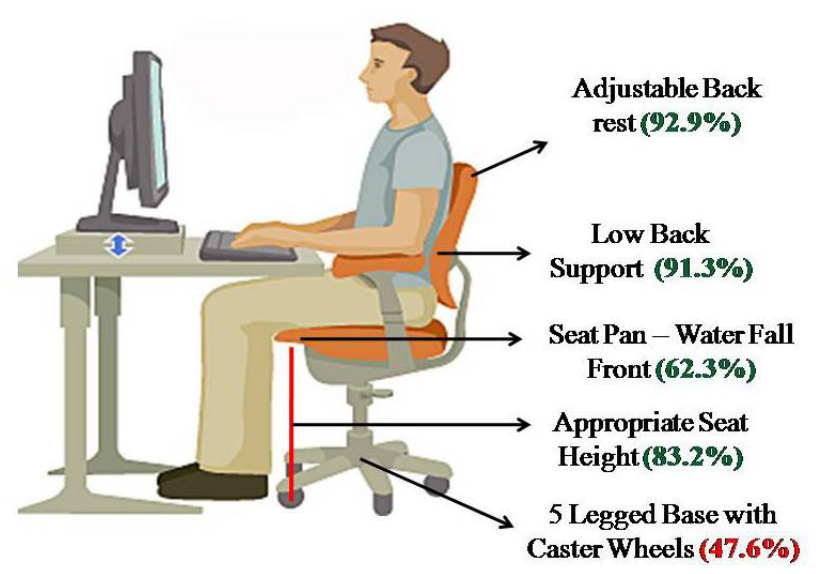

Figure 3. Ergonomic knowledge related to seating.

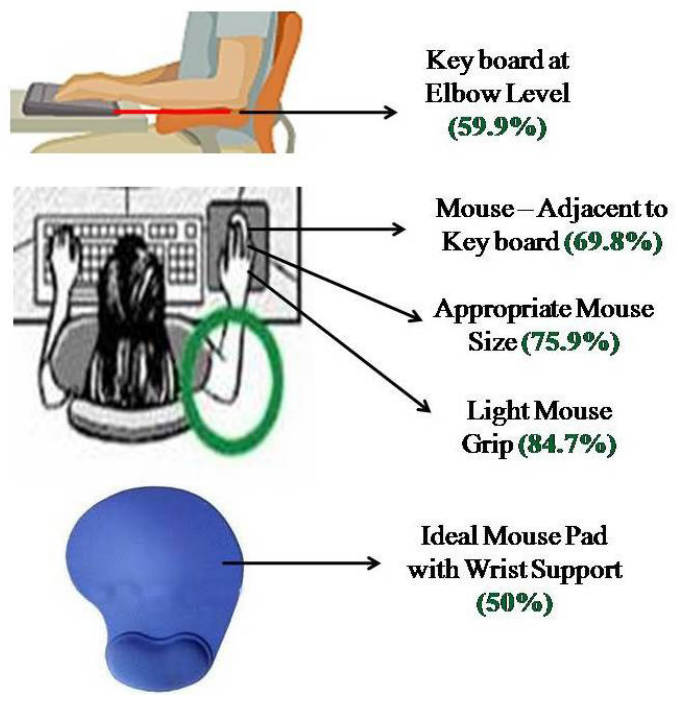

Figure 4. Ergonomic knowledge related to key board/ mouse.

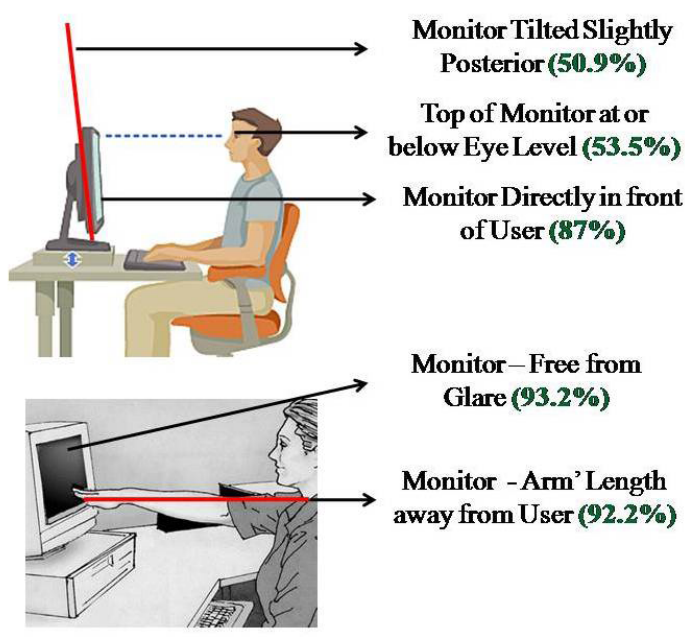

Figure 5. Ergonomic knowledge related to monitor.

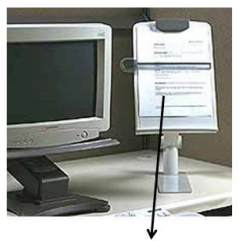

DocumentHolder Adjacent to Monitor (51.9\%)

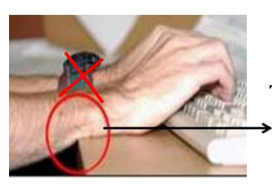

Figure 6. Ergonomic knowledge related to table and accessories. 


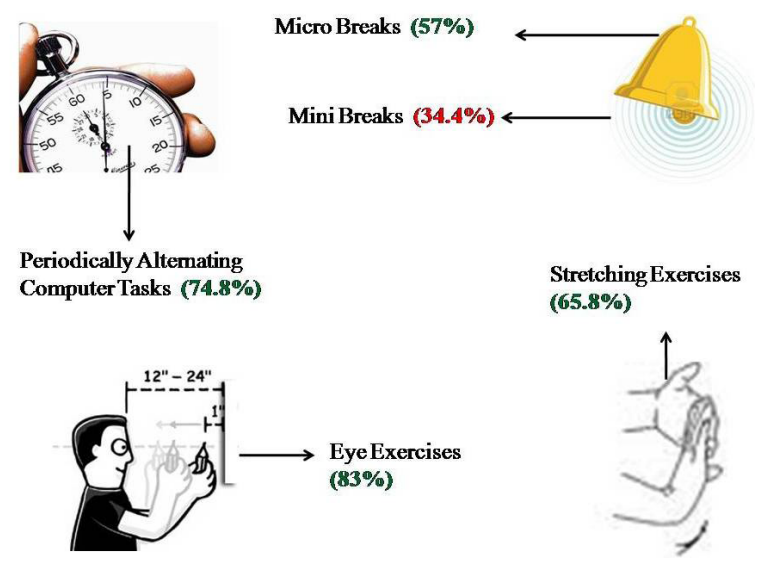

Figure 7. Ergonomic knowledge related to rest breaks and exercises.

The score obtained by the participants in the Knowledge of computer ergonomics section is summarized in Table 3. Majority of the subjects $102(57.6 \%)$ scored in the range of $60-79 \%, 64$ subjects (36.2\%) scored in the range of 40 $59 \%, 11$ subjects $(6.2 \%)$ scored $80 \%$ or above and no one was below $40 \%$.

Table 3. Knowledge of computer ergonomics

\begin{tabular}{lcc}
\hline Score & $\begin{array}{c}\text { Number of Sub- } \\
\text { jects }\end{array}$ & $\begin{array}{c}\text { Percentage of } \\
\text { subjects }\end{array}$ \\
\hline Less than $40 \%$ & 0 & 0 \\
$40-59 \%$ & 64 & 36.2 \\
$60-79 \%$ & 102 & 57.6 \\
$80 \%$ and Above & 11 & 6.2 \\
\hline
\end{tabular}

\section{Discussion}

In this era of digital revolution, there is increased use of computers for education and recreational purposes. Computer users need to know and apply the principles of ergonomics to reduce the risk of development of computer-related health problems including MSDs . To the best of our knowledge, this is the first study to assess the knowledge of Computer ergonomics among Engineering College Students in India. In this study, students reported average weekly computer usage as 18.17 hours, which is lesser than 33.9 hours reported among American graduate students ${ }^{10}$.

The results of this study show that majority of the subjects were unaware of ergonomics and its goals, cumulative trauma disorders, signs \& symptoms and risk factors of MSDs. This finding is in agreement with that of Joshi et al who revealed in their study among computer users of State Agricultural Universities students in India that majority of their participants did not have adequate knowledge about Computer ergonomics ${ }^{11}$. This finding is also similar to the findings of previous study among information technology professionals by Sirajudeen et al., using the same tool ${ }^{8}$.

Working with posture in which joints are in neutral position and naturally aligned minimizes stress and strain on the muscles, tendons, and skeletal system and decreases the risk of developing a MSD ${ }^{12,13}$. Majority of the subjects in this study were able to correctly answer items related to postures of head, neck and trunk, wrist and hand, thigh and feet. However, there was a lack of knowledge about the ideal shoulder and arm postures. Deviations from neutral postures of the shoulder (i.e. flexion and abduction) have been found to be associated with neck and upper limbs symptoms ${ }^{14-16}$.

The chair is the base for comfortable computer work. It must fit the user and be suitable for their tasks. When selecting the chair, Computer users should be aware of certain vital features. The backrest should be large enough to support the user's entire back, including the lumbar region. The height and tilt of the chair should be adjustable and adapt to the lumbar curve ${ }^{17}$. Majority of the subjects were aware about the item related to the low back support (91.3\% correct responses) and adjustable back support (92.9\% correct responses). The seat pan should have a softly padded, rounded front edge (waterfall edge). Straight, unpadded edges leads to compression of thigh region and reduce blood circulation, which can cause pain and numbness in the legs ${ }^{18}$. The user should adjust the height of the seat pan so that the user's knees are at right angles and feet rest flat on the floor or on a stable foot rest. Majority of the subjects knew the item related to the seat pan with waterfall front (62.3\% correct responses) and appropriate seat height (83.2\% correct responses). Chairs should have a stable, five-legged base with caster wheels ${ }^{19}$. Only $47.6 \%$ participants knew the feature regarding base of the chair.

Keyboard height should allow the user to maintain elbow in $90^{\circ}$ flexion ${ }^{20}$. Sauter et al in their study on workstation design and musculoskeletal discomfort found that arm discomfort was associated with keyboard height above the elbow level ${ }^{21}$. In the present study, 59.9\% of participants showed awareness regarding the ideal key 
board position. Mouse should be at the same height as the keyboard, to either side of it. The user's arm should be close to the body for support. The position the mouse should allow the user to maintain a straight, neutral wrist posture $^{22} .69 .8 \%$ of our study participants knew the ideal mouse position.

Appropriate monitor placement reduces the overhead glare and minimizes the exposure to forceful exertions and awkward postures. This reduces possible health risks such as excessive fatigue, eye strain, and neck and back pain. The top of the monitor should be at or slightly below eye level. In this study, only $53.5 \%$ of the participants were aware about the ideal height of the computer monitor. The monitor should be placed at a comfortable distance from the user, where he/she can easily read all text with head and trunk in an upright posture and back supported by the chair. Generally, between 20 and 40 inches (Arm's length) from the eye to the front surface of the computer screen is considered as an ideal viewing distance ${ }^{17}$.Majority of the study participants (92.2\%) were aware about the ideal viewing distance.

If the user has to refer to documents while interacting with the screen or keyboard, it is ideal to use a document holder ${ }^{19}$. Postural loading on the neck muscles can be considerably minimized by using a document holder that presents source material at the same height and at the same distance as the screen ${ }^{23}$. In our study, only $51.9 \%$ of the participants were aware about the need and position of document holder. Seated work requires space (Leg room) to stretch and position the legs in a variety of postures ${ }^{24}$. Majority of the study participants (93.2\%) were aware about the leg room. High repetition tasks or jobs requiring prolonged periods of static posture may interspersed with several, short rest breaks. Only $34.4 \%$ participants were aware about mini breaks. During these breaks, users should be motivated to stand, stretch, and move around. This provides rest and allows the muscles adequate time to recover ${ }^{17}$.

Occupational health and well-being is gaining momentum and initiatives are being made to encourage a culture in which considerable importance is given to the health and safety of the worker ${ }^{25}$. In developing countries such as India, unfortunately adequate attention is not rendered to occupational health and safety issues. Due to poor awareness of the employees and the employers and regulatory inadequacies, cases of work-related injuries were generally not reported. Sound ergonomic knowledge and skills are essential to identify and solve workplace MSD problems. The ergonomics training facilitates the employees to identify the ergonomic hazards and the ways to manage their exposure. Education and training should begin preferably at the student level. College students represent a transitional period between education and working. If the issues of Computer ergonomics are not addressed during their student life, they are more likely to enter their chosen profession with poor computer work behavior.

\section{Limitations}

This study only assessed the knowledge of computer ergonomics among engineering students, but not their practice. Assessment of practical application would have further helped in understanding the risks faced by students in development of MSDs. This could be an area for future research studies. Moreover, as the study was conducted in one state, the findings in this study cannot be generalized to all colleges in different parts of India.

\section{Conclusion}

This research focused the knowledge of computer ergonomics among Computer Science Engineering and Information Technology Students in Karnataka, India. Majority of the subjects were unaware of cumulative trauma disorders, ergonomics and its goals, signs \& symptoms and risk factors for musculoskeletal disorders. The findings of this study emphasize the essentiality of Ergonomic Training for the students to improve the awareness about musculoskeletal disorders and healthy postures and develop a positive attitude towards the importance of Ergonomic Computer Workstation Setup and Exercises. Hence, it is the need of the hour for the university bodies to include Ergonomic Training Programme in educational curricula and prepare the students to enter the work force and excel in their chosen professions.

\section{Conflict of Interest}

None. 


\section{References}

1. Stubbs DA. Ergonomics and occupational medicine: future challenges. Occup Med. 2000; 50(4): 277-82. Available from: https://doi.org/10.1093/occmed/50.4.277

2. Murphy DC. Ergonomics and dentistry. N Y state J. 1997; 63 (7):30-34.

3. Palm N. Ergonomics - OSHA'S next regulatory frontier? J Mich Dent Assoc.1994; 76(5):28-30. PMid:9508902

4. Connelly LB, Woolf A, Brooks P. Cost-Effectiveness of Interventions for Musculoskeletal Conditions. In: Jamison DT, Breman JG, Measham AR et al, editors. Disease Control Priorities in Developing Countries. 2nd ed. Geneva: World Bank; 2006.

5. Karsh B, Moro FBP, Smith MJ. The efficacy of workplace ergonomic interventions to control musculoskeletal disorders: A critical examination of the peer-reviewed literature. Theoret Issues Ergon Sci. 2001; 2: 3-96. Available from: https://doi.org/10.1080/14639220152644533

6. Sirajudeen MS, Shah UN, Mohan N, Somasekharan P. Content validity of a questionnaire to assess the ergonomic knowledge of computer professionals. International Journal of Current Research and Review. 2012; 4(11):114-21.

7. Sirajudeen MS, Pillai PS. Test-retest reliability of a questionnaire to assess the ergonomic knowledge of computer professionals. International Journal of Health and Rehabilitation Sciences. 2015; 4(4):239-43. Available from: https:// doi.org/10.5455/ijhrs.000000094

8. Sirajudeen MS, Pillai PS, Vali GMY. Assessment of knowledge of ergonomics among information technology professionals in India. International Journal of Health and Rehabilitation Sciences. 2013; 2(4):192-7.

9. Wahlstro M J, Svensson J, Hagberg M, Johnson PW. Differences between work methods and gender in computer mouse use. Scand J Work Environ Health. 2000; 26:390-7. Available from: https://doi.org/10.5271/sjweh.559

10. Menéndez CC, Amick BC, Jenkins M, et al. Upper Extremity Pain and Computer Use Among Engineering Graduate Students: A Replication Study. American Journal of Industrial Medicine. 2009; 52(2):113-23. doi:10.1002/ajim.20660. Available from: https://doi.org/10.1002/ajim.20660

11. Joshi P, Karki I, Sharma P. Computer Workstation Ergonomics: Knowledge Testing of State Agricultural Universities (SAU) Students. J Hum Ecol. 2015; 49(3): 335-339.

12. Rizzo TH, Pelletier KR, Serxner S, Chikamoto Y. Reducing Risk Factors for Cumulative Trauma Disorders (CTDs): The Impact of Preventive Ergonomic Training on Knowledge, Intentions and Practices related to Computer Use. Am J
Health Promot. 1997; 11(4):250-3. PMid:10165518 Available from: https://doi.org/10.4278/0890-1171-11.4.250

13. Wahlstro"m J. Ergonomics, musculoskeletal disorders and computer work. Occupational Medicine 2005; 55:168-76. PMid:15857896. Available from: https://doi.org/10.1093/ occmed/kqi083

14. Punnett L, Bergqvist U. Visual display unit work and upper extremity musculoskeletal disorders. Stockholm: National Institute for Working Life; 1997.

15. Tittiranonda P, Burastero S, Rempel D. Risk factors for musculoskeletal disorders among computer users. Occup Med 1999; 14:17-38. PMid:9950008.

16. Marcus M, Gerr F, Monteilh C, et al. A prospective study of computer users: II. Postural risk factors for musculoskeletal symptoms and disorders. Am J Ind Med. 2002; 41:236-49. PMid:11920967. Available from: https://doi.org/10.1002/ ajim. 10067

17. Occupational Safety and Health Administration (OSHA). United States Department of Labor. Available from: http:// www.osha.gov/SLTC/ergonomics/

18. Cornell $\mathrm{P}$. The impact of changes in teaching and learning on furniture and the learning environment. New Directions for Teaching and Learning. 2002; 33-42. Available from: https://doi.org/10.1002/tl.77

19. McKeown C. Office ergonomics: Practical applications. CRC Press; 2007. Available from: https://doi. org/10.1201/9780849379765

20. Laeser KL, Maxwell LE, Hedge A. The effect of computer workstation design on student posture. Journal of Research on Computing in Education. 1998; 31(2):173-88. Available from: https://doi.org/10.1080/08886504.1998.107822 49

21. Sauter S, Dainoff M, Smith M. Promoting health and productivity in the computerized office. New York: Taylor and Francis; 1990.

22. Cook CJ, Kothiyal K. Influence of mouse position on muscular activity in the neck, shoulder and arm in computer users. Applied Ergonomics.1998; 29(6):439-43. Available from: https://doi.org/10.1016/S0003-6870(98)00008-8

23. Pheasant S, Haslegrave C. Bodyspace: Anthropometry, ergonomics and the design of work. 3rd ed. Boca Raton, FL: CRC Press; 2006. PMCid:PMC1361711.

24. Jacobs K. Ergonomics for therapists. 3rd ed. Saint Louis: Mosby; 2008.

25. Khan R, Surti A, Rehman R, Ali U. Knowledge and practices of ergonomics in computer users. J Pak Med Assoc. 2012; 62(3):213-7. PMid:22764450. 